\title{
Codoping studies of physical vapor phase deposition of $\mathrm{SrS}: \mathrm{Cu}$
}

\author{
W. Tong*, Y.B. Xin, T.C. Jones, W. Park, C.J. Summers \\ Phosphor Technology Center of Excellence, Manufacturing Research Center, Georgia Institute of Technology, Atlanta, GA 30332-0560, USA
}

\begin{abstract}
A series of charge compensation investigations on $\mathrm{SrS}: \mathrm{Cu}$ grown by physical vapor phase are reported. In this study, the trivalent ion, Y, was codoped during $\mathrm{SrS}$ growth to substitute on the Sr-site. Although similar EL performance to high temperature annealed sputtered samples was obtained using an annealing temperature of $650{ }^{\circ} \mathrm{C}$, our results indicated that the thermal quenching in this material could only be reduced by charge compensation codoping. Preliminary results show that at $300 \mathrm{~K}$ the brightness of $\mathrm{SrS}: \mathrm{Cu}, \mathrm{Y}$ was only $15 \%$ less than at $10 \mathrm{~K}$. From temperature dependent PL, and high resolution PLE, the physical properties of the defect and the defect reduction mechanisms are determined. (C) 2000 Elsevier Science B.V. All rights reserved.
\end{abstract}

Keywords: EL thin film blue phosphor; $\mathrm{SrS}: \mathrm{Cu}, \mathrm{Y}$; Charge compensation

\section{Introduction}

Within the last year significant progress has been made in the development of blue EL phosphors. Although first reported by Kane et al. in 1985 [1], the commercial potential of this material was established when Sun et al. [2] reported a luminous brightness in $\mathrm{SrS}: \mathrm{Cu}$ of $28 \mathrm{~cd} / \mathrm{m}^{2}$ with lower CIE color coordinates of $x=0.15, y=0.23$ under a $60 \mathrm{~Hz}$ drive by annealing at $810^{\circ} \mathrm{C}$. The broad emission resulted in significant emission intensity below $y=0.15$ for a better saturated blue color. A similar result was also obtained by physical vapor phase deposition (PVD) without high temperature annealing by Tong et al. [3]. These studies showed that $\mathrm{SrS}: \mathrm{Cu}$ was superior than $\mathrm{SrS}: \mathrm{Ce}$ as a blue EL phosphor for the color-by-white approach for manufacturing full color EL displays. However, a large thermal quenching of the luminescent intensity was observed in this material, which caused both a color shift and poor device stability. Temperature dependence PL studies showed that, at room temperature, the emission intensity was reduced to $\sim 40 \%$ of the brightness observed at $10 \mathrm{~K}$. In the previous studies on $\mathrm{SrS}: \mathrm{Ce}$, we presented a methodology to systematically improve the luminescence performance [4]. A similar approach was used to study $\mathrm{SrS}: \mathrm{Cu}$. However, whereas Ce doping in $\mathrm{SrS}$ induces $\mathrm{Sr}$ vacancies that were compensated by Ag [5], the presence of monovalent $\mathrm{Cu}$ on a divalent $\mathrm{Sr}$ site is expected to promote the introduction of sulfur vacancies to maintain charge neutral-

\footnotetext{
* Corresponding author. Tel.: +1-404-894-0815; fax: +1-404-894-5073.

E-mail address: wusheng.tong @gtri.gatech.edu (W. Tong).
}

ity. Thus, a series of codoping studies using the trivalent ion, $\mathrm{Y}$, to substitute on the Sr-site, were investigated; in addition to processes to directly reduce sulfur vacancies via low temperature annealing $\left(<650^{\circ} \mathrm{C}\right)$ under a sulfur atmosphere. From this study, similar EL performance to the high temperature annealed sputtered samples was obtained using an annealing temperature of $650^{\circ} \mathrm{C}$ [6], however, our results also indicated that the thermal quenching in this material could only be reduced by charge compensation codoping. Preliminary results show that at $300 \mathrm{~K}$ the brightness of $\mathrm{SrS}: \mathrm{Cu}, \mathrm{Y}$ was $15 \%$ less than at $10 \mathrm{~K}$.

\section{Experimental}

\subsection{Growth system}

A modified EPI Modular Gen II system with a Balzers TMU1000 turbo-molecular pump, a custom sample loadlock chamber and 5 sample trolley system was employed for this study. The $\mathrm{SrS}: \mathrm{Cu}$ thin films were grown on glass/ ITO/ATO substrates provided by Planar System Inc. For growth, strontium was evaporated thermally from a pyrolytic boron nitride $(\mathrm{pBN})$ crucible. The sulfur was supplied using $t$-butyl mercaptan ( $t$-BuSH) and delivered through a MKS 1159 mass flow controller. This precursor was used since it was easier to control the flow rate with high accuracy and to maintain the system vacuum than with a solid sulfur source. $\mathrm{Cu}$ and $\mathrm{Y}$ metals were evaporated thermally for doping and codoping studies, respectively. In this study the growth rate was controlled to $0.3 \mu \mathrm{m} / \mathrm{h}$ and the total film thickness was $0.6 \mu \mathrm{m}$. $\mathrm{SrS}$ :Cu was grown under high $\mathrm{S}$ to $\mathrm{Sr}$ 


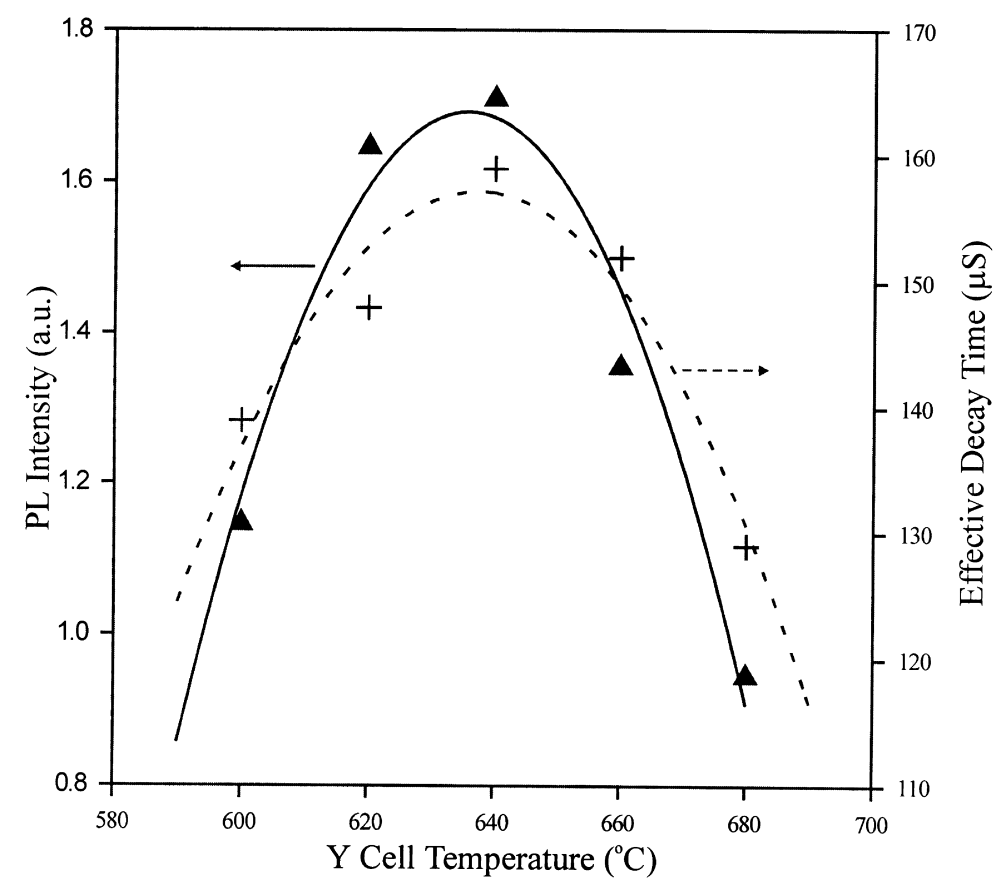

Fig. 1. PL intensity and $10 \mathrm{~K}$ decay time of $\mathrm{SrS}: \mathrm{Cu}, \mathrm{Y}$ as a function of $\mathrm{Y}$ evaporation cell temperatures.

ratios with a growth temperature at $400^{\circ} \mathrm{C}$ as determined from the previous $\mathrm{SrS}: \mathrm{Cu}$ growth studies [3]. The $\mathrm{Cu}$ flux was $2 \times 10^{-8}$ Torr, which gives a $\mathrm{Cu}$ concentration of 2.5 at $\%$ as determined by second ion mass spectroscopy (SIMS) measurements.

\subsection{Characterization}

The surface morphology of the films were studied by secondary electron microscopy (SEM). The photoluminescence spectroscopy (PL) was used to measure the spectral distribution, intensity, and decay time from which the $\mathrm{SrS}: \mathrm{Cu}$ film quality was assessed. PL measurements were performed using a Spectra-Physics BeamLok 2085 Argon Ion laser with $275 \mathrm{~nm}$ single line optics. The samples were mounted in an Air Products DE-202 cryostat and temperature from 10 to $300 \mathrm{~K}$ were obtained using an Air Products closed-cycle helium refrigeration system in conjunction with a Lakeshore 330 temperature controller. The optical signal was collected using a collimating/focusing lens assembly and passed into a Spex 1000M single pass monochromator where a thermoelectrically-cooled Hamamatsu R943-02 GaAs photomultiplier tube (PMT) with photon counting capability detected the signal. The data were then passed to the lab computer for analysis. The photoluminescence excitation (PLE) measurements were made using a Spex $450 \mathrm{~W}$ Xenon lamp/Spex 1681 monochromator setup as a tunable excitation source in conjunction with the sample mount and detection system described above. For the time decay measurements, a Spectra-Physics 73010 MOPO pumped by a GCR $230 \mathrm{Nd}$ :YAG laser which was tunable from $220 \mathrm{~nm}$ to $1.8 \mu \mathrm{m}$ was used as the excitation source. The signal was collected as described above and displayed on a Tektronix 602A oscilloscope. The pulse width was approximately $8.5 \mathrm{~ns}$. Charge deep level transient spectroscopy (QDLTS) was used to study the defect properties. EL devices were fabricated by sputtering a $\mathrm{BaTa}_{2} \mathrm{O}_{6}$ secondary insulator layer followed by e-beam evaporated aluminum contacts.

\section{Results and discussion}

\subsection{Charge compensation and thermal quenching of $\mathrm{SrS}: \mathrm{Cu}, \mathrm{Y}$}

The addition of dopants of different valence results in the creation of additional vacancies to maintain the charge neutrality of the crystal. For example, $\mathrm{Ce}^{3-}$ doping, which adds an extra charge of 1 to the crystal, has been shown to induce a $\mathrm{Sr}$ vacancy $\left(\mathrm{V}_{\mathrm{Sr}}\right)$ in order to compensate the charge imbalance [7]. In this scheme, the $\mathrm{Ce}^{3+}$ ion is compensated by one next nearest neighbor strontium vacancy with a charge of $2^{-}$. Evidence for this argument was observed from EPR studies of SrS:Ce powder [8], as well as sputtered and MBE grown SrS:Ce samples [5]. On the other hand, the doping of monovalent $\mathrm{Cu}$ on a divalent $\mathrm{Sr}$ site is expected to promote the introduction of sulfur vacancies $\left(\mathrm{V}_{\mathrm{S}}\right)$ to maintain charge neutrality. By introducing $1^{+}$valence atoms, such as $\mathrm{Na}, \mathrm{K}$, the charge imbalance of the $3^{+}$valence luminescent center has been successfully compensated, thus, minimizing the lattice distortion in powder phosphors [9]. This greatly improved the efficiency of the phosphor without sacrificing the blue chromaticity. However, it has 


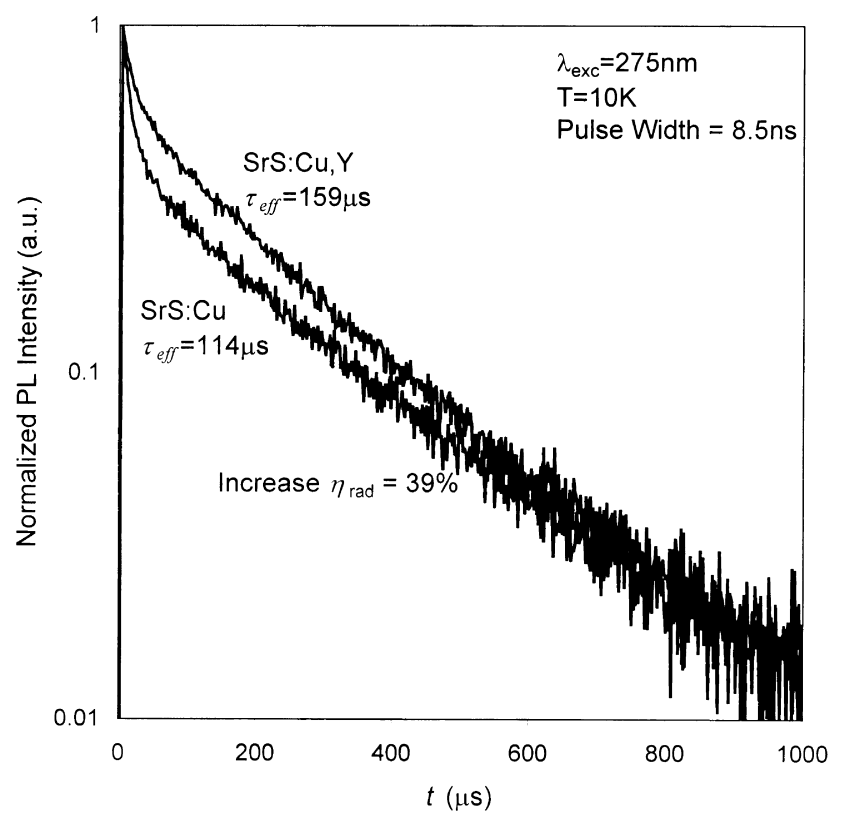

Fig. 2. Time decay characteristics for $\mathrm{SrS}: \mathrm{Cu}, \mathrm{Y}$ vs. $\mathrm{SrS}: \mathrm{Cu}$.

been found that the same dopants are difficult to incorporate using thin-film growth techniques. We have successfully achieved charge compensation in PVD thin films of SrS:Ce which greatly improved the EL brightness and blue chromaticity by using $\mathrm{Ag}$ codoping [5]. Ideally, a charge compensating atom should have a compatible vapor pressure at the growth temperature and similar ion size so that it can be incorporated properly into the cation site. Therefore, for this study Y was identified as possible charge compensating ion for PVD grown SrS: $\mathrm{Cu}$ thin films.

Fig. 1 shows the room temperature PL intensity and $10 \mathrm{~K}$ decay time of $\mathrm{SrS}: \mathrm{Cu}, \mathrm{Y}$ as a function of $\mathrm{Y}$ cell temperatures. Both the PL intensity and decay time peaked at a $\mathrm{Y}$ flux corresponding to a cell temperature of $640^{\circ} \mathrm{C}$ indicating that this growth condition gave the optimized Y concentration for improved sample quality. SIMS studies indicated a monotonic increase of $Y$ concentration with the increase of cell temperatures. Unfortunately, the absolute concentration could not be determined due to the lack of an Y standard reference for the SIMS measurements. The effective decay time increased from 139 to $159 \mu \mathrm{s}$ as the $\mathrm{Y}$ cell temperature was increased from 600 to $640^{\circ} \mathrm{C}$, and then decreased to $128 \mu \mathrm{s}$ at $680^{\circ} \mathrm{C}$. We attribute the maximum in the decay time at $640^{\circ} \mathrm{C}$ as an indication that the energy transfer processes were minimized for this $\mathrm{Y}$ concentration. Therefore, the fewest defects were formed indicating that this sample exhibited the best crystallinity in the concentration series. The decrease in the decay time above this temperature indicated that either the $\mathrm{Y}$ codoping was creating more defects than it was compensating, or that the $\mathrm{Y}$ center was acting as non-radiative center, or both. The time decay data for the $\mathrm{SrS}: \mathrm{Cu}$ and $\mathrm{SrS}: \mathrm{Cu}$, Y systems is shown in Fig. 2. As can be seen, the decay time for the optimum codoped sample was $159 \mu$ s at $10 \mathrm{~K}$ and was also more exponential

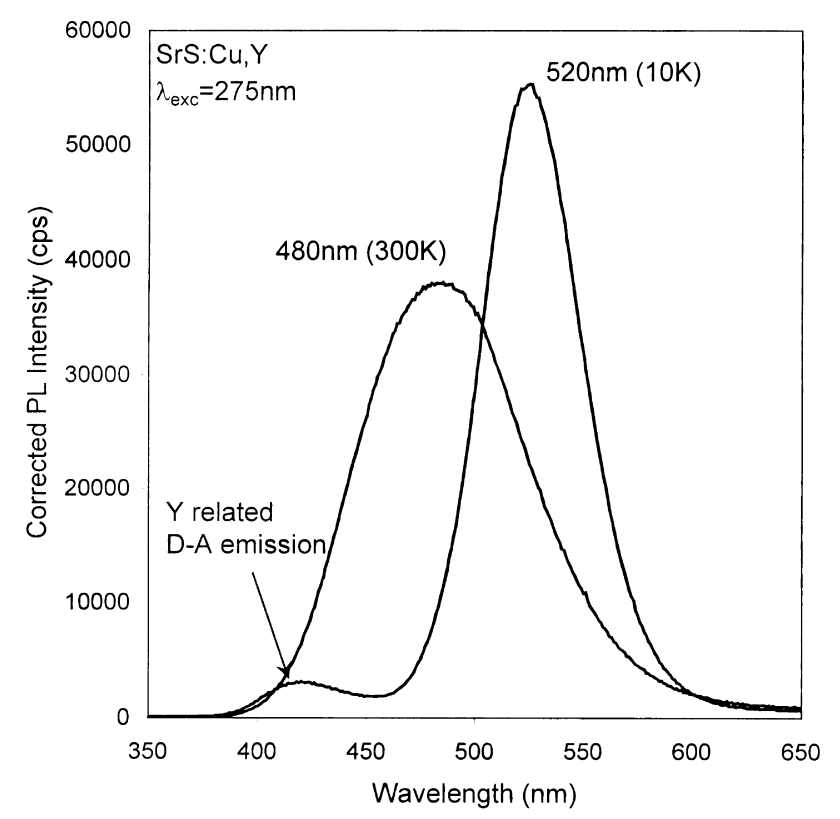

Fig. 3. Temperature dependence of $\mathrm{SrS}: \mathrm{Cu}, \mathrm{Y}$ and $\mathrm{SrS}: \mathrm{Cu}$.

as compared to the time decay of $114 \mu$ s measured for the undoped sample, confirming that energy transfer processes were suppressed in $\mathrm{SrS}: \mathrm{Cu}, \mathrm{Y}$. The ratios of the two time constants was

$$
\frac{\tau(\mathrm{SrS}: \mathrm{Cu}, \mathrm{Y})}{\tau(\mathrm{SrS}: \mathrm{Cu})}=1.39
$$

indicated that the radiative efficiency and also the quantum efficiency were $39 \%$ higher in the $\mathrm{SrS}: \mathrm{Cu}, \mathrm{Y}$ system.

Shown in Fig. 3 are the temperature dependent PL results for both $\mathrm{SrS}: \mathrm{Cu}$ and $\mathrm{SrS}: \mathrm{Cu}, \mathrm{Y}$. For $\mathrm{SrS}: \mathrm{Cu}$ the thermal quenching began at $100 \mathrm{~K}$ and the luminescent intensity quickly dropped to $58 \%$ of the $10 \mathrm{~K} \mathrm{PL}$ intensity at room temperature. On the other hand, the PL intensity measured from $\mathrm{SrS}: \mathrm{Cu}, \mathrm{Y}$ slightly increased between 75 and $100 \mathrm{~K}$ and then for higher temperatures decreased by only $15 \%$ compared to the maximum intensity measured at $75 \mathrm{~K}$. This signified that the non-radiative energy loss was suppressed greatly. After the optimization of $\mathrm{SrS}: \mathrm{Cu}, \mathrm{Y}$ process it is possible to further suppress the thermal quenching as we have demonstrated in $\mathrm{SrS}: \mathrm{Ce}, \mathrm{Ag}$ charge compensation studies [10].

\section{2. $\mathrm{SrS}: \mathrm{Cu}, \mathrm{Y}$ defect studies}

In order to effectively improve EL device efficiency it is necessary to identify the major defects which degrade film quality and to fully understand their properties. In the studies on SrS:Ce [4], methods of reducing or compensating vacancies were identified. In the first method it was suggested the addition of $\mathrm{Mn}$ and/or $\mathrm{Zn}$ decreased the native $\mathrm{Sr}$ vacancy concentration as the dilute $\mathrm{SrZn}($ orMn)S alloy became less ionic. In the second method, the extra change induced by $\mathrm{Ce}^{3+}$ doping was suppressed by codoping of $\mathrm{Ag}$ 


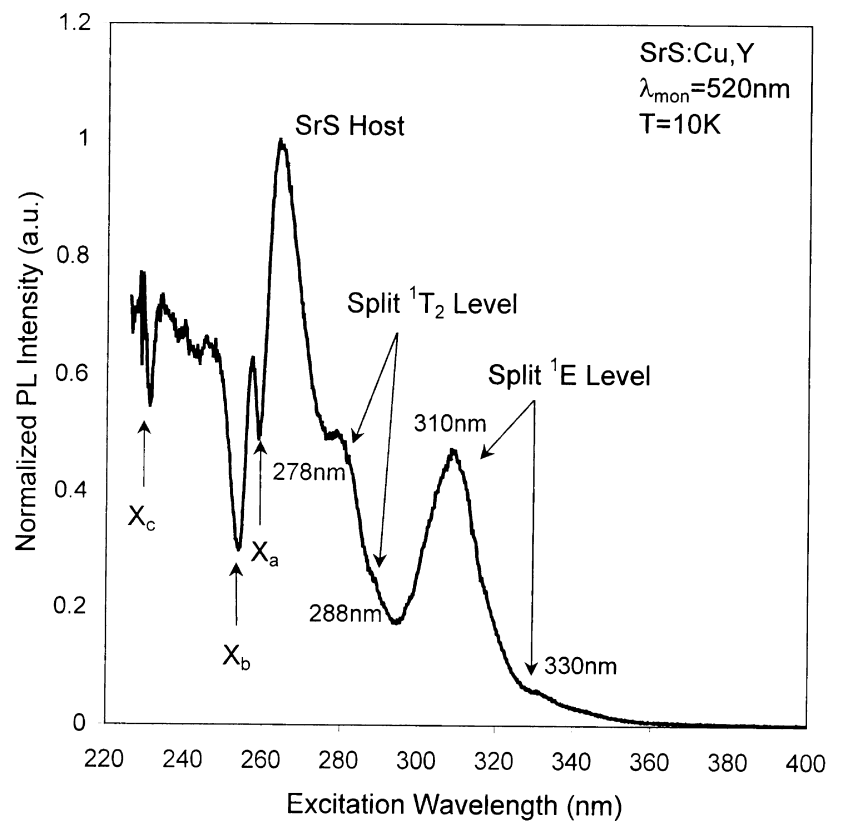

Fig. 4. PLE spectrum of $\mathrm{SrS}: \mathrm{Cu}, \mathrm{Y}$.

for charge compensation. In the same study, a detailed model was established to explain the emision spectrum red shift due to the $\mathrm{Ce}^{3+}$ doping in the SrS:Ce thin films. In this model the charge imbalance induced $\mathrm{Sr}$ vacancy is close to the $\mathrm{Ce}^{3+}$ ion and changes its environment, which splits the lowest exited state for lower emission energy.

It has been found that post annealing of $\mathrm{SrS}: \mathrm{Cu}$ in a sulfur environment can greatly increase both EL and PL luminescent intensity. QDLTS studies of these samples indicate a reduction in the sulfur vacancy density. SEM studies also found that the sulfur annealing had a profound effect to stimulate the grain growth of $\mathrm{SrS}: \mathrm{Cu}$. Based on these studies a possible energy loss model was discussed in Ref. [6]. However, sulfur annealed SrS:Cu still exhibited a large thermal quenching indicating the existence of a non-radiative energy transfer path which could not be eliminated by annealing. The most probable candidate responsible for the thermal quenching is non-radiative energy transfer to defects and not multiphonon emission since the transition energy $(2.582 \mathrm{eV})$ of $\mathrm{SrS}: \mathrm{Cu}$ is much larger than the phonon energy of $\mathrm{SrS}\left(\hbar \omega_{\mathrm{LO}}=35 \mathrm{meV}\right)$. The most likely defect source is sulfur vacancies since monovalent copper ions substitute for the divalent strontium ions and no intentional codoping was made. Thus one sulfur vacancy $\left(\mathrm{V}_{\mathrm{S}}\right)$ is needed for every two $\mathrm{Cu}^{+}$ions in order to maintain charge neutrality somewhat analogous to the $\mathrm{SrS}: \mathrm{Ce}$ situation. The Y codoping study results support this argument. However, the results also showed an entire different interaction behavior between the $\mathrm{Cu}$ ion and $\mathrm{V}_{\mathrm{S}}$, as compared with the shortrange interaction between the $\mathrm{Ce}$ ion and $\mathrm{V}_{\mathrm{Sr}}$ discussed previously. Fig. 3 shows that the emission spectra for $\mathrm{SrS}: \mathrm{Cu}, \mathrm{Y}$ at 10 and $300 \mathrm{~K}$. Note that the $\mathrm{Y}^{3+}$ codoped sample exhibited a broad emission centered at $480 \mathrm{~nm}$ at

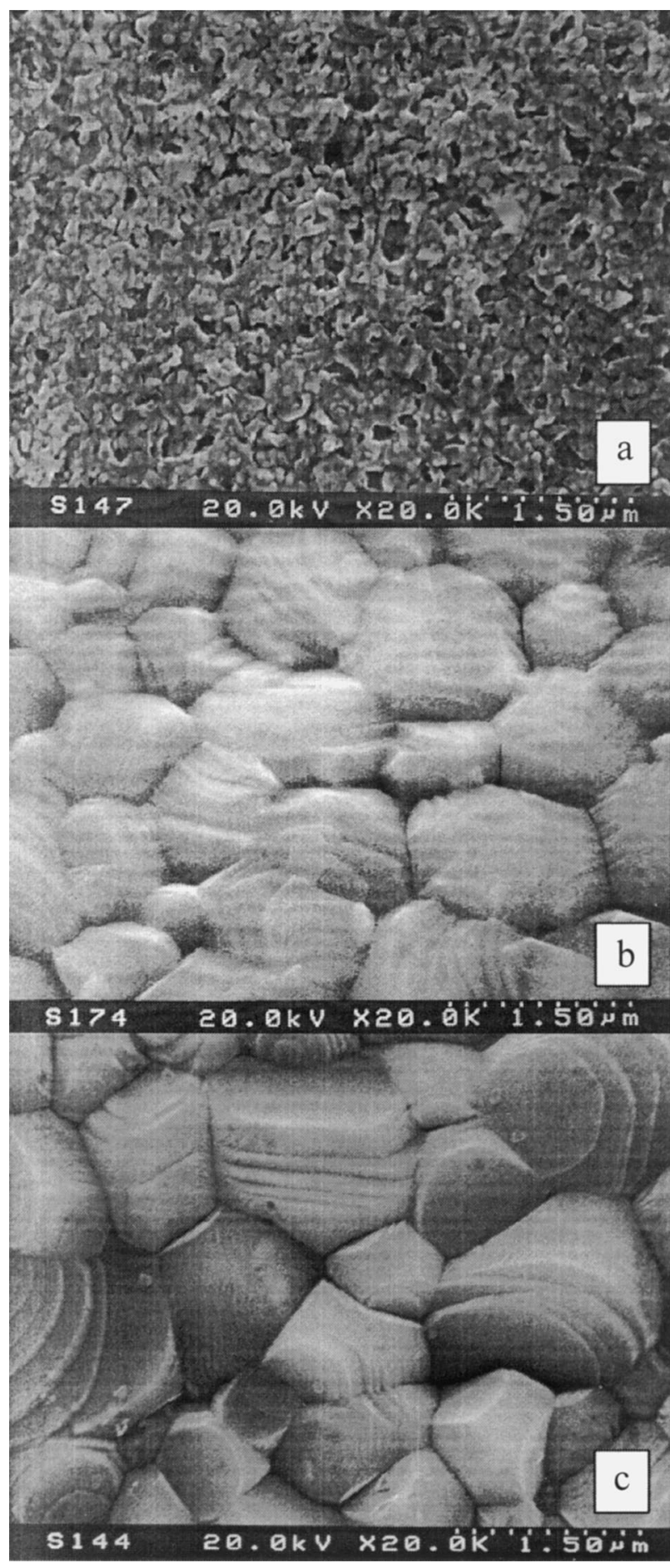

Fig. 5. Surface morphologies of $\mathrm{SrS}: \mathrm{Cu}, \mathrm{Y}$ annealed at $650^{\circ} \mathrm{C}$ for: (a) $15 \mathrm{~min}$; (b) $17 \mathrm{~min}$; and (c) $20 \mathrm{~min}$.

room temperature and a green emission centered at $520 \mathrm{~nm}$ at $10 \mathrm{~K}$ which was identical to the emission characteristics for the singly $\mathrm{Cu}$ doped case. The PLE spectrum for the $\mathrm{Y}^{3+}$ codoped sample at $10 \mathrm{~K}$, shown in Fig. 4, was found to be identical to the singly $\mathrm{Cu}$ doped sample exhibiting excitation bands only at 278, 288, 310 and $320 \mathrm{~nm}$. This indicated that the presence of the $\mathrm{Y}^{3+}$ ion did not affect the energy 


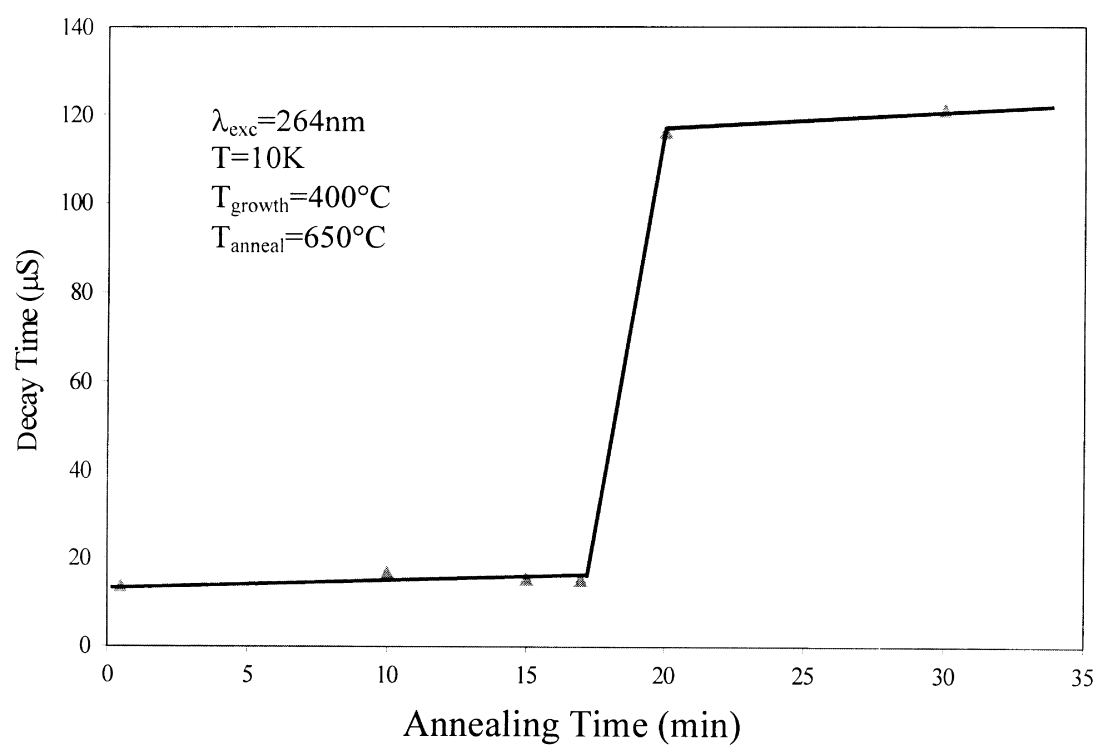

Fig. 6. SrS:Cu, Y decay time as a function of anneal time.

level structure of the $\mathrm{Cu}^{+}$ion. The sulfur vacancy, which is compensated by $\mathrm{Y}^{3+}$, is therefore, well removed from the $\mathrm{Cu}^{+}$ion as it does not affect the crystal symmetry and thus the interaction between $\mathrm{Cu}$ and $\mathrm{V}_{\mathrm{S}}$ is expected to be long range. Consequently, it is very likely that the energy loss in $\mathrm{SrS}: \mathrm{Cu}$ is through phonon mediated energy transfer to sulfur vacancies.

\subsection{SrS:Cu, Y grain growth studies}

Similar to $\mathrm{SrS}: \mathrm{Cu}$, sulfur annealing also stimulate grain growth in $\mathrm{SrS}: \mathrm{Cu}, \mathrm{Y}$. The surface morphologies of $\mathrm{SrS}: \mathrm{Cu}$, $\mathrm{Y}$ annealed at $650^{\circ} \mathrm{C}$ for 15,17 , and $20 \mathrm{~min}$ are shown in Fig. 5(a)-(c), respectively. It is clear that the fast grain expansion occurred between 15 and 17 min. Similarly, the decay time studies as a function of annealing time, given in Fig. 6, showed an abrupt increase in the effective time constant from 15 to $120 \mu \mathrm{s}$, but for a slightly longer anneal time (between 17 and $20 \mathrm{~min}$ ). These suggested that during annealing the film re-crystallization process was completed through a fast grain expansion followed by a short relaxation time which then produced material of a much higher quality at the microscopic level.

\section{Conclusions}

A series of codoping and annealing studies for VPD grown $\mathrm{SrS}: \mathrm{Cu}$ have been reported. A much better thermal quenching behavior was achieved using $\mathrm{Y}$ as a charge compensator during the growth. Preliminary results showed a less than $15 \%$ in luminescent intensity reduction at room temperature, as compared to the intensity at $10 \mathrm{~K}$, and a $39 \%$ increase in the radiative efficiency by $\mathrm{Y}$ codoping.

PL and PLE results showed an identical $\mathrm{Cu}^{+}$emission spectrum and the same excitation bands only at 278, 288,
310 and $330 \mathrm{~nm}$ with $\mathrm{Y}$ codoping, indicating a long-range interaction between the $\mathrm{Cu}$ ion and $\mathrm{V}_{\mathrm{S}}$. It is suggested that the energy loss process in $\mathrm{SrS}: \mathrm{Cu}$ was by phonon-assisted energy transfer to the non-radiative $\mathrm{V}_{\mathrm{S}}$ centers.Detailed post annealing time studies showed that for high quality $\mathrm{SrS}: \mathrm{Cu}$, $\mathrm{Y}$ thin film materials, the recrystallization was completed by a fast grain expansion followed by a short time relaxation period during the sulfur annealing process.

\section{Acknowledgements}

This work is supported by the Next Generation Display Consortium under DARPA Contract MDA972-95-3-0029.

\section{References}

[1] J. Kane, W. Harty, M. Ling, P.N. Yocom, SID '85 Digest, 1985, p. 163.

[2] S.S. Sun, E. Dickey, J. Kane, P.N. Yocom, SID '97 Conference Record, SID, Santa Ana, 1997. p. 301.

[3] W. Tong, Y. Xin, M. Chaichimansour, J. Choi, T. Jones, W. Park, B.K. Wagner, C.J. Summers, Proceedings of the 9th International Workshop on Inorganic and Organic Electroluminescence, September, Bend, Oregon, 1998.

[4] W. Tong, L. Zhang, M. Chaichimansour, B.K. Wagner, C.J. Summers, SID '97 Conference Record, SID, Santa Ana, 1997, p. 305.

[5] W. Tong, L. Zhang, W. Park, M. Chaichimansour, B.K. Wagner, C.J. Summers, Appl. Phys. Lett. 71 (16) (1997) 2268.

[6] W. Tong, Y.B. Xin, W. Park, C.J. Summers, Appl. Phys. Lett. 74 (10) (1999) 1379.

[7] K. Takahashi, K. Shibuya, A. Kondo, J. Crystal Growth 117 (1992) 979.

[8] W.L. Warren, K. Vanheusden, C.H. Seager, D.R. Tallant, J.A. Tuchman, S.D. Silliman, D.T. Brower, J. Appl. Phys. 80 (12) (1996) 7036.

[9] C.N. King, J. SID 4 (3) (1996) 153.

[10] W. Tong, Proceedings of SPIE 3636 (1999) 74-82. 